Bulgarian Academy of Sciences. Space Research and Technology Institute. Aerospace Research in Bulgaria. 30, 2018, Sofia

DOI: https://doi.org/10.3897/arb.v30.e03

\title{
SOLAR CYCLE BY A LOOK OF HIGH SPEED SOLAR WIND STREAMS VARIATION
}

\author{
Simeon Asenovski \\ Space Research and Technology Institute - Bulgarian Academy of Sciences \\ e-mail: asenovski@space.bas.bg
}

\begin{abstract}
In this paper are presented variation of the solar wind parameters during last four solar cycles $(21 \div 24)$ with focus on the high speed solar wind streams $(H S S)$ condition. The averaged values of the parameters for every cycle are calculated and discussed. The results show that Earth is under the HSS influence more than $50 \%$ of the total time in each of the last four solar cycles. This fact determines the importance of the studding the behavior of the HSS.
\end{abstract}

\section{Introduction}

High speed solar wind streams (HSS) are one of the solar wind components which originate from unipolar open magnetic field areas known as coronal holes $[1,2]$. HSS cause relatively weak, but recurrent and long-lasting geomagnetic storms [3]. The variations of geomagnetic activity closely follow the variations of the number and intensity of HSS within the solar cycle [4]. Coronal holes are the largest and in most geoeffective position during the sunspot declining phase [4], when the second maximum in the geomagnetic activity is observed. In Fig. 1 is presented an SDO/AIA image (Solar Dynamics Observatory/ Atmospheric Imaging Assembly) of the coronal hole CH869 on 15 June 2018. CH869 have been rotated into an Earth facing position on June 19-21. 


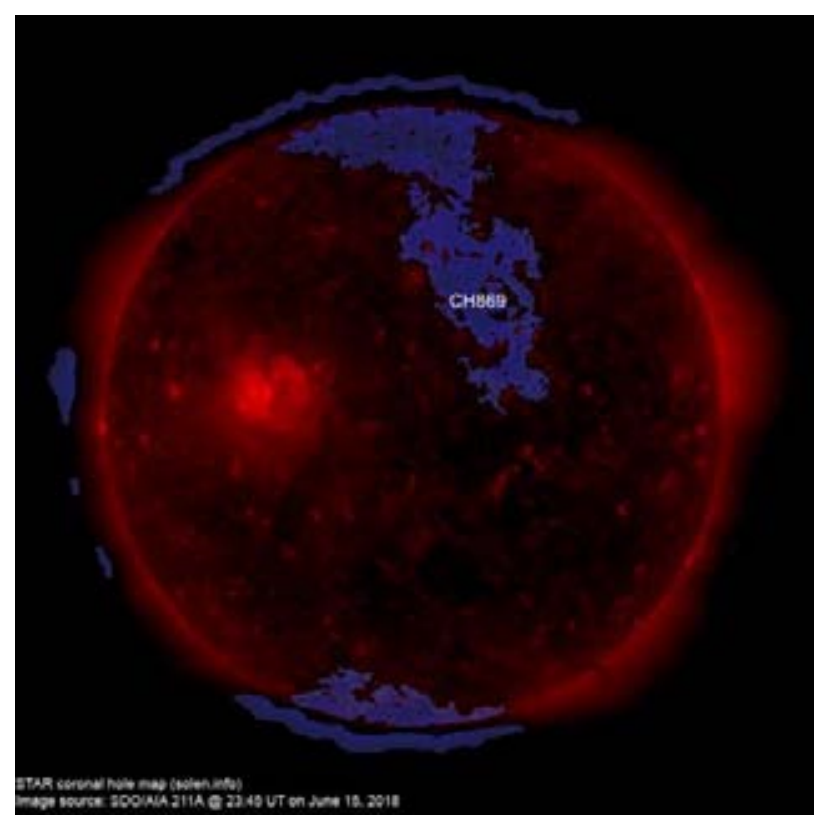

Fig. 1. SDO/AIA image of the coronal hole CH869 at 23:45UT on 15 June 2018 (http://www.solen.info/solar/)

Solar cycle (SC) is generally associated with the 11 year sunspot cycle (Schwabe, 1843) and numerous studies concerning Sun and solar-terrestrial physics are related with it. In Table 1 are presented duration of the last eight SC $(17 \div 24)$. The $24^{\text {th }}$ is supposed to end within 2018 with duration approximately of $\sim 11$ years.

Table 1. Duration of the last eight Solar cycles $(17 \div 24)$

\begin{tabular}{|c|c|c|c|}
\hline Cycle & Started & Finished & Duration (years) \\
\hline Solar cycle 17 & 1933 September & 1944 February & 10.4 \\
\hline Solar cycle 18 & 1944 February & 1954 April & 10.2 \\
\hline Solar cycle 19 & 1954 April & 1964 October & 10.5 \\
\hline Solar cycle 20 & 1964 October & 1976 June & $\mathbf{1 1 . 7}$ \\
\hline Solar cycle 21 & 1976 June & 1986 September & $\mathbf{1 0 . 3}$ \\
\hline Solar cycle 22 & 1986 September & 1996 May & $\mathbf{9 . 7}$ \\
\hline Solar cycle 23 & 1996 May & 2008 January & $\mathbf{1 1 . 7}$ \\
\hline Solar cycle 24 & 2008 January & 2018 & $\sim 11$ \\
\hline
\end{tabular}


In the current study, the focus will be on the HSS during the last four SC $(21 \div 24)$. Here the differences of the main parameters (Temperature $[K]$, Speed $[\mathrm{km} / \mathrm{s}]$, Density [cm-3], Magnetic field [nT]) during the cycles will be discussed. In Fig. 2 are shown the variations of the sunspot number for these cycles. As it can be seen, the last $24^{\text {th }} \mathrm{SC}$ is characterized with the lowest values of the sunspot number during the course of the whole cycle in comparison with the other cycles.

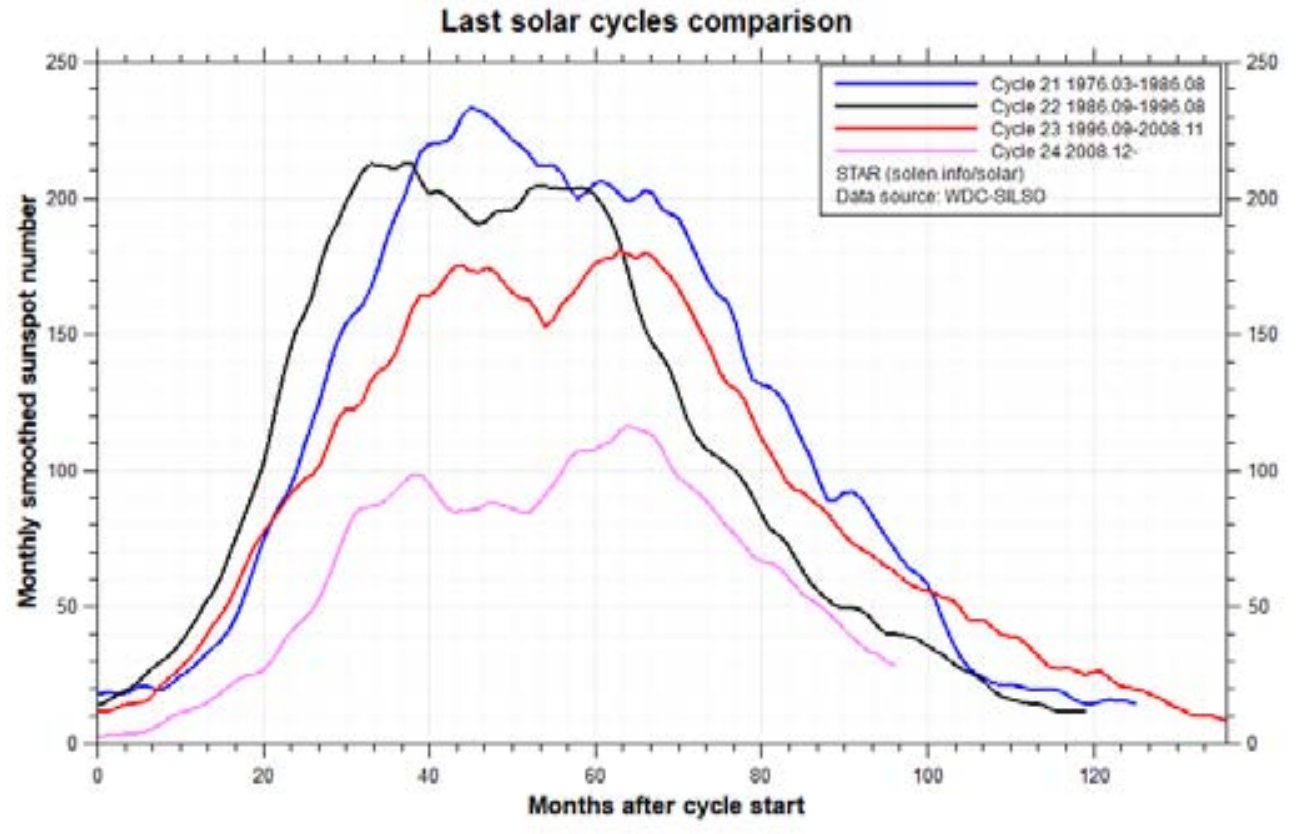

Fig. 2. Comparison of the monthly smoothed sunspot number variation for the last four SC (21-24) (http://www.solen.info/solar/)

Parker suggested that the properties of solar wind flow depend on the solar activity cycle [7]. Several years later series of space probe experiments, as Lunik and Venera [8], Explorer 10 [9] and Venus Mariner 2 [10] confirmed the Parker's theory.

\section{Data}

In attempt to identify the periods when Earth is under the influence of the HSS the hourly values of the plasma parameters gathered in OMNI data base are used (http://omniweb.gsfc.nasa.gov/) [11]. The criteria for identifying a HSS include an increase of the solar wind speed by at least $100 \mathrm{~km} / \mathrm{s}$ in no more than one day to at least $450 \mathrm{~km} / \mathrm{s}$ for at least five hours [12]. 


\section{Results}

In Tables 2-5 are shown the averaged values of the main solar wind parameters (Different magnetic field components [nT], Temperature of the plasma $[\mathrm{K}]$, Density $[\mathrm{N} / \mathrm{c}]$, Speed $[\mathrm{km} / \mathrm{s}]$, Flow pressure [nPa]) for the last four SC for different solar wind conditions - Slow solar wind with speed less than $450 \mathrm{~km} / \mathrm{s}$, fast solar wind with speed over $450 \mathrm{~km} / \mathrm{s}$ but different from HSS, coronal mass ejection (CME) and HSS. For every SC are presented the total numbers of hours in which Earth is under the influence of these conditions. The last three rows have shown the averaged values of the geomagnetic $D s t$ index and the sunspot number $R$.

Table 2. Averaged values of the main solar wind properties during SC21

\begin{tabular}{|c|c|c|c|c|}
\hline & $\begin{array}{c}\text { Slow SW } \\
\mathbf{V} \leq \mathbf{4 5 0} \mathbf{~ k m} / \mathbf{s}\end{array}$ & $\begin{array}{c}\text { Fast SW } \\
\mathbf{V}>\mathbf{4 5 0} \mathbf{~ k m} / \mathbf{s}\end{array}$ & CME & HSS \\
\hline Hours & 6120 & 900 & 143 & 7878 \\
\hline Scalar B, nT & 5.41 & 5.45 & 11.13 & 5.85 \\
\hline Bx, nT & -0.22 & -0.02 & 0.30 & -0.36 \\
\hline By, nT & 0.37 & -0.05 & -0.45 & 0.34 \\
\hline Bz, nT & 0.12 & 0.12 & -0.56 & 0.22 \\
\hline T, $\mathrm{K}$ & 64495 & 184070 & 69757 & 178230 \\
\hline Dens, N/c & 10.78 & 5.20 & 8.67 & 5.60 \\
\hline Speed, km/s & 370.45 & 520.92 & 394.45 & 512.18 \\
\hline Pressure, nPa & 2.75 & 2.65 & 2.54 & 2.66 \\
\hline $\mathbf{R}$ & 15.73 & 21.57 & 28.44 & 13.49 \\
\hline Dst, nT & -5.70 & -14.03 & -27.41 & -17.79 \\
\hline
\end{tabular}

At SC21 the number of hours in which HSS is observed is 7878 which is more than $50 \%$ of the total time of the cycle. Here we can see that the average temperature during HSS is significantly larger than the temperature of the slow solar wind and comparable with the temperature of the fast solar wind. Here it must be noticed what is the difference between fast solar wind and HSS. According to the criteria of HSS there is a requirement concerning duration which is at least five hours. Normally the averaged sunspot number is the largest during the condition of CME. 
Table 3. Averaged values of the main solar wind properties during SC22

\begin{tabular}{|c|c|c|c|c|}
\hline & $\begin{array}{c}\text { Slow SW } \\
\mathbf{V} \leq \mathbf{4 5 0} \mathbf{~ k m} / \mathbf{s}\end{array}$ & $\begin{array}{c}\text { Fast SW } \\
\mathbf{V}>\mathbf{4 5 0} \mathbf{~ k m} / \mathbf{s}\end{array}$ & CME & HSS \\
\hline Hours & 3289 & 271 & 105 & 7161 \\
\hline Scalar B, nT & 5.50 & 6.73 & 9.45 & 5.90 \\
\hline Bx, nT & -0.43 & -0.09 & -1.52 & 0.15 \\
\hline By, nT & 0.04 & -0.51 & -0.68 & 0.03 \\
\hline Bz, nT & 0.24 & -0.39 & -0.61 & 0.00 \\
\hline T, K & 54590 & 148250 & 73523 & 146090 \\
\hline Dens, N/c & 11.83 & 7.45 & 7.08 & 6.14 \\
\hline Speed, km/s & 367.02 & 486.46 & 422.70 & 507.98 \\
\hline Press, & 2.96 & 3.41 & 2.36 & 2.78 \\
\hline R & 18.46 & 16.99 & 20.87 & 16.81 \\
\hline Dst, nT & -4.41 & -16.79 & - & -19.98 \\
\hline
\end{tabular}

Similarly to SC21, with its 7161 hours the next SC22 is characterized with more than $50 \%$ of the total time of the cycle in which to the Earth reach HSS. During this time the average density and flow pressure have the lowest values in comparison to the values when it is observed slow and fast solar wind as well as CME.

Table 4. Averaged values of the main solar wind properties during SC23

\begin{tabular}{|c|c|c|c|c|}
\hline & $\begin{array}{c}\text { Slow SW } \\
\mathbf{V} \leq \mathbf{4 5 0} \mathbf{~ k m} / \mathbf{s}\end{array}$ & $\begin{array}{c}\text { Fast SW } \\
\mathbf{V}>\mathbf{4 5 0} \mathbf{~ k m} / \mathbf{s}\end{array}$ & CME & HSS \\
\hline Hours & 7283 & 342 & 132 & 9811 \\
\hline Scalar B, nT & 3.86 & 4.58 & 8.42 & 4.68 \\
\hline Bx, nT & 0.46 & -1.61 & 0.46 & -0.19 \\
\hline By, nT & -0.57 & 1.13 & -0.41 & 0.08 \\
\hline Bz, nT & 0.05 & 0.08 & 1.13 & 0.02 \\
\hline T, K & 42251 & 124360 & 61981 & 132840 \\
\hline Dens, N/c & 7.02 & 3.88 & 5.54 & 4.06 \\
\hline Speed, km/s & 347.06 & 519.55 & 399.77 & 517.74 \\
\hline Press, & 1.46 & 2.03 & 1.57 & 1.87 \\
\hline R & 5.16 & 10.32 & 8.98 & 4.97 \\
\hline Dst, nT & -1.98 & -13.32 & -6.25 & -12.42 \\
\hline
\end{tabular}

During SC23, time of HSS (9 811 hours) is more than $75 \%$ the total time. This fact determines condition of relatively high temperature, low density and pressure. During the period when Earth is under the slow solar wind the average temperature of the plasma reach its lowest value of $42251 \mathrm{~K}$.

The general picture has been slightly changed for the last SC24. While the relative duration of the HSS for the cycle remains more than $50 \%$ of the total time, 
the most of the parameters differ from the previous cycle. Here can be noticed that the average speed drop under $500 \mathrm{~km} / \mathrm{s}$ for HSS while the temperature increase more than $200000 \mathrm{~K}$.

Table 5. Averaged values of the main solar wind properties during SC24

\begin{tabular}{|c|c|c|c|c|}
\hline & $\begin{array}{c}\text { Slow SW } \\
\text { V } \leq \mathbf{4 5 0} \mathbf{~ k m} / \mathbf{s}\end{array}$ & $\begin{array}{c}\text { Fast SW } \\
\mathbf{V}>\mathbf{4 5 0} \mathbf{~ k m} / \mathbf{s}\end{array}$ & CME & HSS \\
\hline Hours & 7981 & 655 & 128 & 8690 \\
\hline Scalar B, nT & 5.01 & 5.12 & 12.68 & 5.55 \\
\hline Bx, nT & 0.10 & -1.12 & -0.76 & 0.27 \\
\hline By, nT & -0.02 & 0.97 & 0.12 & -0.09 \\
\hline Bz, nT & -0.13 & -0.21 & -0.58 & -0.11 \\
\hline T, K & 90625 & 262550 & 80164 & 205240 \\
\hline Dens, N/c & 10.33 & 4.47 & 8.34 & 6.97 \\
\hline Speed, km/s & 362.73 & 511.37 & 402.60 & 463.32 \\
\hline Press, & 2.39 & 2.19 & 2.51 & 2.53 \\
\hline R & 10.29 & 7.85 & 12.87 & 11.07 \\
\hline Dst, nT & -6.34 & -25.42 & -29.84 & -17.76 \\
\hline
\end{tabular}

\section{Conclusion}

This work presents a study for variation of the solar wind parameters for the different state, as slow and fast solar wind, coronal mass ejection and high solar wind speed. The averaged parameters are calculated and discussed for the last four solar cycles $(21 \div 24)$. The result can be summarized in the following statements:

- The time in which Earth is under the HSS influence is more than $50 \%$ of the total time in each of the last four solar cycles.

- At SC23 the HSS influence is more than $75 \%$ of the total time.

- Slow solar wind temperature during SC23 reach its lowest value of $42251 \mathrm{~K}$.

- The averaged parameters of the fast solar wind and HSS have similar values.

- During the last SC24 the averaged HSS speed drops under $500 \mathrm{~km} / \mathrm{s}$ while HSS temperature increases more than $200000 \mathrm{~K}$.

\section{Acknowledgments}

This work was supported by the National Science Fund under Competition for financial support for projects of junior researchers - 2016, grant № DM 04/4 from 14.12.2016 "Investigation of the impulsive solar activity agents throughout the 11-year solar cycle". 


\section{References}

1. Tsurutani, B. T., W. D. Gonzalez, A. L. C. Gonzalez, F. Tang, J. K. Arballo, M. Okada, Interplanetary origin of geomagnetic activity in the declining phase of the solar cycle, J. Geophys. Res., 1995, 100, 21717.

2. Tsurutani, B. T., W. D. Gonzalez, A. L. C. Gonzalez, F. L. Guarnieri, N. Gopalswamy, M. Grande, Y. Kamide, Y. Kasahara, G. Lu, I. Mann, R. McPherron, F. Soraas, and V. Vasyliunas. Corotating solar wind streams and recurrent geomagnetic activity: A review. J. Geophys. Res., 2006, 111, A07S01, DOI:10.1029/2005JA011273.

3. Borovsky, J. E., M. H. Denton, Differences between CME-driven storms and CIR-driven storms, J. Geophys. Res., 2006, 111, A7.

4. Richardson, I. G., H. V. Cane. Solar wind drivers of geomagnetic storms during more than four solar cycles, J. of Space Weather \& Space Clim., 2012, A01, DOI:10.1051/swsc/2012001.

5. Phillips, J. L., S. J. Bame, W. C. Feldman, J. T. Gosling, C. M. Hammond, D. J. McComas, B. E. Goldstein, M. Neugebauer, E. E. Scime, and S. T. Suess. Ulysses Solar Wind Plasma Observations at High Southerly Latitudes, Science, 1995, 1268, 1030-33.

6. Schwabe, T. Sonnen-beobachtungen im jahre 1843, Astr. Nachrichten, 1843, 21, 233-236.

7. Parker, E. N. Interaction of the Solar Wind with the Geomagnetic Field, Physics of Fluids, 1958, 1, 171-87.

8. Gringauz, K. I., V. G. Kurt, V .I. Moroz, and I. S. Shklovskii. Results of Observations of Charged Particles Observed Out to R=100, $000 \mathrm{~km}$, with the Aid of Charged-Particle Traps on Soviet Space Rockets, Astronomicheskii Zhurnal, 1960, 37, 716.

9. Bonetti, A., H. S. Bridge, A. J. Lazarus, B. Rossi, and F. Scherb. Explorer 10 Plasma Measurements, Journal of Geophysical Research, 1963, 68, 4017.

10. Neugebauer, M., C. W. Snyder. Solar Plasma Experiment, Science, 1962, 138, 1095-97.

11. King, J. H., N. E. Papitashvili. Solar wind spatial scales in and comparisons of hourly wind and ACE plasma and field data, J. Geophys. Res., 2005, 110, 2104, 2005.

12. Richardson, I. G., H. V. Cane. Regions of abnormally low proton temperature in the solar wind (1965-1991) and their association with ejecta, J. Geophys. Res., 1995, 100, A12, 23397-412.

\section{СЛЬНЧЕВИЯ ЦИКЪЛ ОТ ГЛЕДНА ТОЧКА НА ВАРИАЦИИТЕ НА ВИСОКОСКОРОСТНИТЕ ПОТОЦИ СЛЬНЧЕВ ВЯТЬР}

\section{С. Асеновски}

\section{Резюме}

В работата са представени вариациите на параметрите на слънчевия вятър за последните четири сльнчеви цикъла $(21 \div 24)$ с подчертано внимание на условията на високоскоростен сльнчев вятър. Средните стойности на параметрите за всеки цикъл са пресметнати и дискутирани. Резултатите показват, че Земята е под въздействието на високоскоростен слънчев вятър повече от $50 \%$ за всеки от последните четири слънчеви цикъла. Този факт обуславя важността от изследване на поведението на тези потоци. 